\title{
A FORMAÇÃO DO SUJEITO E PODER DISCIPLINAR EM MICHEL FOUCAULT E SUA RELAÇÃO COM O CAPITALISMO
}

\author{
Genivaldo de Souza Santos ${ }^{1}$, João Ferreira da Silva Júnior ${ }^{2}$ \\ ${ }^{1}$ Universidade Estadual Paulista - UNESP, Marília, SP. ${ }^{2}$ Universidade do Oeste Paulista - UNOESTE, Mestrado em \\ Educação, Presidente Prudente, SP. E-mail: joaoferreira1975@bol.com.br
}

\begin{abstract}
RESUMO
O intuito deste artigo é apresentar à luz do pensamento de Michel Foucault o quanto o sistema econômico capitalista modelou e constituiu os seus sujeitos (objetos) no tecido social, especialmente pela instituição escolar, através de suas tecnologias disciplinares, ou seja, uma fabricação e uma conformação dos ideais do poder instituído. A pesquisa bibliográfica, ora realizada, tem como referencial teórico Michel Foucault e seus intérpretes que avaliam a questão do poder disciplinar na formação e na acomodação do sujeito principalmente pela instituição escolar moderna. As análises dos resultados desta pesquisa bibliográfica têm como objetivo demostrar o quanto a escola está alinhada com o poder instituído quando trata da formação do sujeito. Permitindo assim inferir que a escola não forma, apenas reproduz ou leva a conformação ao tecido social.

Palavras-chave: Sujeito. Instituição escolar.Poder disciplinar. Formação. Capitalismo.

\section{THE FORMATION OF THE SUBJECT AND DISCIPLINARY POWER ON MICHEL FOUCAULT AND ITS RELATION TO CAPITALISM}

\begin{abstract}
The purpose of this paper is to present the light of the thought of Michel Foucault as the capitalist economic system modeled and made his subjects (objects) in the social fabric, especially by the academic institution, through its disciplinary technologies, manufacturing and conformation of the ideals of institutional power. The literature, now held, has the theoretical Michel Foucault and his interpreters who evaluate the issue of disciplinary power in the formation and subject the accommodation mainly by modern educational institution. Analysis of the results of this literature are intended to demonstrate how the school is aligned with the power instituted when comes to the formation of the subject. Allowing infer that the school no form, just playing or leads to shaping the social fabric.
\end{abstract}

Keywords: Subject. School institution. Disciplinary power. Formation. Capitalism. 
INTRODUÇÃO

Através dos estudos de Michel Foucault (2002), este artigo versará sobre a formação do sujeito disciplinado, ou objeto de manipulação, por meio dessa sociedade e o quanto a escola e outras instituições fechadas contribuem para a perpetuação desse comportamento, através de sua vigilância e punição. Principalmente o quanto o poder disciplinar tem conseguido se constituir através de sua força por meio da disciplinarização do espaço, tempo e corpos. A pesquisa em desenvolvimento é de cunho qualitativa e bibliográfica, que lançará mão de levantamentos de textos teóricos que tratam desta questão no pensamento de Michel Foucault de seus intérpretes.

O assunto principal desta pesquisa será o poder disciplinar que o saber-poder impõe a esta sociedade, reduzindo-os ao ser objeto, ou uma quase mecânica de ser que produz ao limite nessa sociedade capitalista, em outras palavras, produzir ao nível da mecânica. Questionando quanto a disciplina, como componente de uma força oculta ou silenciosa serve para obter maior eficiência e controle social, principalmente como regulamentação de prática punitiva em todo seio social.

\section{A GÊNESE DE UM PARADIGMA, OS CORPOS DÓCEIS}

Em sua obra Vigiar e Punir, publicada em 1975, que tem como subtítulo A história da violência nas prisões, Michel Foucault (2002) traça um percurso histórico do homem moderno desde o final do feudalismo passando pelo início do capitalismo até a sua consolidação, no início do século XVIII, procurando entender o comportamento e os saberes do homem.

Foucault (2002) nos chama a atenção para o fato de que no início do século XVIII uma nova economia de mercado começa a se impor, gerando uma nova concepção de homem, que necessita de uma nova formação, objetivando atender aos interesses dessa nova economia de mercado, o capitalismo. Consequentemente, inicia-se um processo de docilizacão dos corpos nas instituições de sequestro, como escola, hospital, asilo e exército. Segundo Foucault (2002, p 117), trata-se de um corpo "que se manipula, se modela, se treina, que obedece, responde, se torna hábil ou cujas forças se multiplicam".

Esse novo homem então passaria a sofrer em todos os sentidos da sua vida uma coerção ininterrupta, exercida pelo Estado, de uma forma minuciosa, controlando o corpo e impondo uma forma de docilizacão e utilidade, segundo (FOUCAULT, 2002, p. 118), podendo chamar isso de "disciplinas" tornando essa no início do século XVIII "fórmulas gerais de dominação".

A disciplina fabrica corpos submissos e exercitados, corpos "dóceis". A disciplina aumenta a força do corpo (em termos econômicos de utilidade) e diminuem essas mesmas forças (em termos político de obediência). Em uma palavra: ela dissocia o poder do corpo; faz dele por um lado uma "aptidão" 
uma "capacidade" que ela procura aumentar; e inverte por outro lado a energia, a potência que poderia resultar disso, e faz dela uma relação de sujeição estrita. Se a exploração econômica separa a força e o produto do trabalho, digamos que a coerção disciplinar estabelece no corpo o elo coercitivo entre uma aptidão aumentada e uma dominação acentuada. (FOUCAULT, 2002, p. 119).

Foucault (2002) chama essa técnica minuciosa de microfísica do poder, que desde século XVIII vem ganhando espaço, cada vez mais amplo na sociedade como uma teia, cobrindo todo o corpo social. Uma técnica astuta com grande poder de difusão, silenciosa, com aparência angelical, embora fortemente suspeita, uma coerção silenciosa e sem grandeza, sendo essas que proporcionaram a mudança na execução da pena ou do regime punitivo, definido por Foucault (2002, p. 120), “[...] uma anatomia política do detalhe".

A era clássica não a inaugurou; ela acelerou, mudou sua escala, deu- Ihe instrumentos precisos, e talvez tenha encontrado alguns ecos para ela no cálculo do infinitamente pequeno ou na descrição das características mais tênues dos seres naturais. Em todo o caso o "detalhe" era já há muito tempo uma categoria da teologia e do ascetismo: todo o detalhe é importante, pois aos olhos de Deus nenhuma imensidão é maior que um detalhe, e nada há tão pequeno que não seja querido por uma dessas vontades singulares. (FOUCAULT, 2002, p. 120),

Foi nesse detalhe que se inaugurou sem dificuldade todas as minucias da educação cristã, da pedagogia, ou do aparato militar, ou seja, de todas as formas de treinamento, levando o homem ao disciplinamento na igreja, nas fábricas e no exército.

Entretanto, Foucault (1975) nos chama atenção para o fato que a disciplina somente consegue ter o seu efeito pedagógico ser for trabalhado em lugares fechados, nunca em campo aberto. A disciplina exige um lugar heterogêneo e fechado em si mesmo. Segundo Foucault (2002), os colégios buscaram nos conventos o seu modelo, sendo o internato o regime mais perfeito para esse ideal. Os quartéis foram e são de suma importância para proteger o capital e as riquezas que passaram a ser acumuladas em forma de máquinas e bens, ao contrário do feudalismo que mensurava a riqueza pela quantidade de terra fértil.

Em 1719, a ordenação francesa prescreve a construção de várias centenas de quartéis, em 1745 já havia na França 320 quartéis e aproximadamente 200.000 soldados (FOUCAULT, 2002, p. 122). Os quartéis deveriam ter "uma muralha de dez pés de altura, para manter as tropas em ordem e em disciplina e que o oficial esteja em condição de responder por ela".

As fábricas da época começaram a copiar a arquitetura e os procedimentos dos conventos e quartéis, as fábricas eram verdadeiras fortalezas, uma cidade fechada, as portas eram abertas, 
quando o sino era tocado, e fechadas imediatamente após entrar todos os trabalhadores, sendo abertos novamente só no fim do turno, impedindo agitações, saques, roubos e principalmente proteger a produção dominando as forças de trabalho. A clausura é uma forma de manter o corpo vigiado, sendo mais fácil para sancioná-lo, medir as qualidades ou o mérito e apreciá-los.

Na disciplina, os elementos são intercambiáveis, pois cada um se define pelo lugar que ocupa na série, e pela distância que o separa dos outros. A unidade não é, portanto nem o território (unidade de dominação), nem o local (unidade de residência), mas a posição na fila: o lugar que alguém ocupa numa classificação de intervalos que se pode percorrer sucessiva. A disciplina, arte de dispor em fila, e da técnica para as transformações dos arranjos. Ela individualiza os corpos por uma localização que não os implanta, mas o distribui e os faz circular em uma rede de relações. (FOUCAULT, 2002, p. 125),

\section{A ESCOLA COMO PRODUTORA DE SUJEITOS}

Segundo Michel Foucault (2002), o poder disciplinar permeia várias instituições como prisões, quartéis, fábricas, hospitais e escolas, sendo a escola a instituição que mais contribuiu, na idade moderna, para a docilização ou conformidade dos corpos. Trata-se de um espaço de perpetuação da disciplina e saber, onde a disciplina é fixada e aceita de forma um tanto sutil pela população.

O capitulo terceiro de Vigiar e Punir explicita o quanto a escola exercita e mantém o controle disciplinar evocando um trabalho na qual se possa alcançar, um sistema de engrenagem, em que o professor esteja inteiramente ligado a um todo escolar, em outras palavras, que um possa se parecer com o outro. Esse trabalho é feito através de uma técnica sutil de disciplina ou quase um jogo, pois é através de recompensas e premiações para os melhores alunos, castigos e punições para os piores alunos. Todo esse jogo é para que os alunos sejam dóceis e úteis, quanto mais um se aparecer com o outro melhor também será a instituição.

No regime da sociedade disciplinar como a nossa, a punição, ao discriminar os comportamentos dos indivíduos, passa a diferenciá-los, a hierarquizá-los em termos de uma conformidade a ser seguida, ou seja, a punição não objetiva sancionar a infração, mas controlar, qualificar o indivíduo, não interessando o que ele fez, mas o que é, será ou possa ser. As punições são da ordem do exercício, implicando o aprendizado intensificado, multiplicado, repetido, em suma, punir é exercitar. (GUIMARÃES, 2003, p.86).

A punição ocorre de várias maneiras, principalmente pelas micropenalidades, ao desviar de seu comportamento, o aluno é levado a praticar exercícios de aprendizagem intensificados, repetições de tarefa, perda do intervalo, ou seja, a escola perpetua um sistema de punição e 
recompensa. Segundo Cruz e Freitas (2011, p.7), “O controle de todos esses movimentos garante que os indivíduos saiam da escola com uma docilidade e utilidade ideal ao mundo capitalista".

Foucault nos apresenta quatro tipos de organização disciplinar do indivíduo: celular, orgânica, genética e combinatória. A organização escolar consiste em colocar cada aluno num lugar específico, cada aluno tem a sua carteira e cada carteira, um aluno. Significa preencher toda a sala de aula de modo organizado e que possa assim, vigiar o comportamento de cada aluno, rompendo com todo o tipo de comportamento dito perigoso para o bom andamento da aula. Os lugares estabelecidos e individuais permitem que todos os alunos sejam controlados e que todos produzam de forma igual. (CRUZ e FREITAS 2011, p.7).

A escola como instituição fechada ou de sequestro, tornou-se uma máquina de ensinar, transformando uma multidão, confusa esem os saberes necessários, desorganizados, em uma multidão adaptada a servir como mão de obra organizada e passiva. Nesse contexto, a escola profissionalizante age de forma natural como caminho para a evolução humana contrapondo aos bons selvagens que nela entram para serem os intelectuais pacificados, a escola dessa forma exerce uma tutela moral sobre os indivíduos.

A escola então tem um papel de destaque nessa sociedade, ou seja, ela tem um papel ampliado como instituição de regulação social, principalmente com o avanço cada vez mais onipresente do neoliberalismo. Hoje se assiste uma educação como mercadoria. Formando sujeitos-objetos, frios, individualistas, desconectados com o mundo real e principalmente alheios (alienados) as suas próprias histórias. O papel da escola foi de tirar as pessoas da sociedade de soberania para uma sociedade estatal.

Vimos que o grande objetivo das tecnologias de vigilância é, pela via disciplinar, fabricar corpos dóceis, como já mostraram alguns autores, tal fabricação se dá por um duplo movimento: somos primeiramente objetificados numa rede disciplinar, composta por microscópicas divisões espaciais e temporais; quase ao mesmo tempo, vamos nos enxergando como sujeito nessa rede - uma rede que parece invisível para nós, motivo pela qual pensamos que o disciplinamento é natural. Como expliquei em outro lugar, a análise genealógica permite que se compreendam "as inúmeras práticas que acontecem no ambiente escolar como técnicas que se combinam e dão origem a uma verdadeira tecnologia, cujo fim é tanto alcançar os corpos em suas ínfimas materialidades quanto imprimir-lhes o mais permanente possível determinadas disposições sociais. Mas se o corpo é o alvo desse conjunto de técnicas ortopédica, não se pode esquecer que, para Foucault, é por intermédio do corpo que se fabrica a alma, visto que a alma é, ao mesmo tempo, o produto do investimento político do corpo e um instrumento de seu domínio. Assim, trata-se, ao mesmo tempo, o produto do investimento político do corpo e um instrumento do seu domínio. Assim, trata-se, ao mesmo tempo, de uma ortopedia física e moral. (VEIGA-NETO, 2011, p.70). 
Veiga-Neto (2007) no seu livro Foucault \& a Educação, nos chama a atenção para o fato de que por várias vezes Foucault afirma que a escola foi a instituição que mais operou as individualizações disciplinares, tendo um papel de destaque na sociedade moderna. Segundo ele, a escola foi concebida e montada como a maior máquina dessa sociedade moderna, capaz fazer dos corpos o objeto do poder disciplinar, tornando-os dóceis e passiveis de manipulação.

A escola, depois da família, seria a instituição de sequestro que todos devem passar, ou seja, é uma máquina de modelar o corpo social. Ela conseguiu conectar ao mesmo tempo em seus espaços a relação entre poder e saber, fazendo dos saberes uma legitimadora dos poderes sociais ativos, constituindo assim os seus sujeitos objetos.

[...] a escola foi a instituição moderna mais poderosa, ampla, disseminada e minuciosa a proceder a íntima articulação entre o poder e o saber, de modo a fazer dos saberes a correria (ao mesmo tempo) transmissora e legitimadora dos poderes que estão ativos nas sociedades modernas e que instituíram e continuam instituindo o sujeito.(VEIGA-NETO, 2011, p. 114).

As avaliações escolares representa, um grande indicador desse tipo de poder, pois tem o caráter de medir, comparar, analisar e principalmente de classificar sendo ao mesmo tempo um objeto do conhecimento, mas acima de tudo uma preparação para a manipulação do poder sobre o sujeito. Como relata Cruz e Freitas (2011, p.9), “O exame é uma prática disciplinar que normaliza ao mesmo tempo em que vigia, ele permite qualificar, classificar, vigiar e punir, combinando técnicas da hierarquia que vigia e da sanção que busca normalizar".

O nascimento da Pedagogia como "ciência da educação" deveu-se, pois, ao advento da tecnologia dos exames, tornando possível a metrificação, a quantificação da aprendizagem, colocando sua organização no âmbito da prévia organização estratégica. O professor, assim, além de ser aquele que tem o poder de transmitir conhecimentos, dado seu saber acumulado, é também aquele que tem o poder de cobrar dos alunos o conhecimento que Ihes foi transmitido, tornando o seu poder muito mais "visível", muito mais palpável e menos abstrato, pois sua é também a mão que pune, através do castigo físico ou simplesmente através da nota e das complicações na vida acadêmica, no caso de o aluno não ser bem sucedido no exame. (GALLO, 2004,p 94)

Foucault (2011) aponta para o fato de que todo o conhecimento impregnado sobre o aluno faz da escola um local da execução pedagógica, conduzindo a formação do saber ao exercício pleno do poder. É então uma pedagogia funcionando como ciência na era da escola das avaliações, exames e recompensas classificatórias, em outras palavras, legitimando um determinado tipo de poder. 
O poder deve ser analisado como algo que circula, ou melhor, como algo que só funciona em cadeia. Nunca está localizada aqui ou ali, nunca está nas mãos de alguns, nunca é apropriado como uma riqueza ou bem. O poder funciona e se exerce em rede. Nas suas malhas os indivíduos não só circula, mas estão sempre em posição de exercer este poder e de sofrer sua ação: nunca é o alvo inerte ou consentido do poder, são sempre centros de transmissão. Em outro termo, o poder não se aplica aos indivíduos, passa por eles. (FOUCAULT, 1985, p. 183).

Veiga-Neto (2007) relata que a educação tem um caráter e um papel nos processos de fixação dos arranjos pedagógicos modernos dos saberes, sendo que as epistemologias sociais criaram leis e regras que moldam o mundo, ou seja, são essas epistemologias, positivismo, naturalismo, construtivismo e histórica crítica que dão sentido para todo conhecimento da ciência da vida. Entretanto Foucault (1985), com uma nova teoria se afasta de todas estas epistemologias.

\section{CONSIDERAÇÕES FINAIS}

Talvez poderíamos dizer, diante de toda essa realidade, que o capitalismo promoveu uma maior acessão dos pobres aos bens e riqueza de um país, ao mesmo tempo em que nunca se encarcerou tanto como agora, para ilustrar, nos Estados Unidos a população carcerária passa de 2.000.000 (Dois milhões) sujeitos, no Brasil há algo em torno de 607,000 (Seiscentos e sete mil), segundo dados do Conselho Nacional de Justiça - CNJ e do Sistema Integrado de Informações Penitenciárias - InfoPen do Departamento Penitenciário Nacional/ministério da Justiça julho/2015. Fruto, segundo Loic Wacquant, (2011), de uma desordem gerada pelo desemprego em massa, pela imposição do trabalho assalariado precário imposto a todo população, que são vista apenas como máquina produtora.

Fica evidente que o modelo de educação imposto ou executado de forma sutil, como algo quase natural, tem fracassado quando o que está em jogo é o despertar de um sujeito sensível à causa humana. Entretanto essa mesma educação contribuiu de forma ampla para a acomodação e docilização dos corpos ao saber-poder, uma conformação e uma fabricação do sujeito à tecnologia disciplinar. Levado o sujeito a ser apenas objeto ou máquina de produção do capitalismo, cujo fruto é um sujeito frio que não consegue cuidar nem de si próprio.

A escola ensina seres acorrentados, que ao saírem dela, deverão aprender apensar, mas como? Se o professor ensina conceitos que, por vezes, não pertencem à sua realidade, e nessa irrealidade, o aluno vai pra casa e não consegue fazer sequer uma união entre escola e vida, dar sentido social ao que aprende, tornam-se indivíduos que aceitam, sem nenhum questionamento, os saberes e a verdade constituída. (CRUZ e FREITAS 2011, p.10). 
É necessário, portanto, uma escola que não seja apenas uma instituição dos saberes, mas também do ser, onde as relações humanas sejam construídas em harmonia com a natureza, e que o hoje seja a alavanca do sucesso e felicidade das próximas gerações. Por isso os professores devem encontrar brechas, nestas instituições fechadas e fazer a diferença ou de uma vez por toda encontrar novas maneiras de fazer educação.

\section{REFERÊNCIAS}

CRUZ, Priscila; Freitas, Disciplina, Controle Social e Educação Escolas: Um breve Estudo à luz do Pensamento de Michel Foucault. Disponível em:<http://revistas.marilia.unesp.br/index.php/levs/article/view/1674/1422 Acesso em 17 de novembro de 2014.

FOUCAULT, Michel. Microfísica do Poder. 5a edição. Ed. Trad. Roberto Machado.Rio de Janeiro: Graal, 1985.

Vigiar e Punir. 26a edição.Trad. Raquel Ramalhete. Petrópolis: Vozes, 2002.

GALLO, Silvio. Repensar a educação: Foucault. Revista educação e realidade. Porto Alegre: UFRGS, 2004.

Disponível

em: <http://www.seer.ufrgs.br/educacaoerealidade/article/download/25420/14746.> Acesso em 17 de novembro de 2014.

GUIMARÃES, Áurea Maria. A dinâmica da violência escolar: Conflito e ambiguidade. Autores Associados, Campinas-SP, 1996.

LOIC, Wacquant, As prisões da miséria. Trad. André Telles. Rio de Janeiro: Zahar, 2011.

MACHADO, Roberto. Por uma Genealogia do Poder. In: FOUCAULT, M. Microfísica do Poder. $5^{\circ}$ ed. Rio de Janeiro: Graal, 1985.

MINISTÉRIO DA JUSTIÇA. Departamento Penitenciário Nacional (Brasil). Síntese das Ações do Departamento Penitenciário: ano 2013. Distrito Federal: DEPEN, 2015.

NERY, Sergio. A Disciplina nas Organizações Empresariais- Um estudo à luz do pensamento de Michel Foucault. 2008. Dissertação (Mestrado em Filosofia)-Pontifícia Universidade Católica de São Paulo, São Paulo, 2008. Disponível em: <http://www.dominiopublico.gov.br/download/texto/cp059468.pdf. $>$ Acesso em 17 de novembro de 2014.

VEIGA-NETO, Alfredo. Foucault e a Educação. 3 ed. Belo Horizonte: Autêntica, 2011. 